\title{
Health Education in Diabetic Population: Current Practice and Future Challenges
}

\author{
Muhammad A Siddiqui ${ }^{1}$, Zeeshan Ahmed ${ }^{2, *}$, Adeel Ahmed Khan ${ }^{3}$
}

\begin{abstract}
${ }^{1}$ MBBS, PGD HCM, M Sc Diabetes, PhD Research Scholar, School of Health Sciences, Queen Margaret University, Edinburgh, UK ${ }^{2}$ MBBS, Community Medicine Resident, Department of Community Medicine, Dow University of Health Sciences, Karachi, Pakistan ${ }^{3}$ MBBS, Community Medicine Resident, Department of Community Health Sciences, A gha Khan University Hospital, Karachi, Pakistan
\end{abstract}

\begin{abstract}
The aim of this review is to discuss the role of health education, self-management and multidisciplinary approach and how they can improve to produce a framework for better practice. Diabetes is a growing problem in all over the world. It is as sociated with severe co mp lications if it is not adequately controlled. Diabetes patients need to develop a range of competencies that allow them to take greater controlover the treat ment of their disease. This requires education that promotes health whilst respecting individuals' self-perceived needs and voluntary choices. However, such concept is not new in the field of diabetes; health professionals are still struggling with how to administer it successfully. Diabetic patients can be educated toward greater autonomy, but all health professionals are not ready to work in partnership with them. This review indicates that there are number of important changes which need to be taken. There is a need to gain better understanding of diabetes management and theoretical principles underlying patient empowerment and education. In order to achieve better outcomes and effective health care services, collaboration of different health care professional working in different setup is required.
\end{abstract}

Keywords Diabetes, Diabetes Education, Patient Education, Self-care, Self-management

\section{Background}

Diabetes mellitus is a disease marked by high levels of blood glucose resulting from deficiency in insulin production, insulin action, or both. It can lead to serious complications and premature death, but people with diabetes can take steps to control the disease and lower the risk of complications ${ }^{1}$. The World Health Organization (WHO) estimates that by the year 2030 the prevalence of diabetes will reach to 366 million cases and the mortality rate of sufferers will be doubled $^{2}$. Diabetes is the commonest and rapidly growing health problem in all age group in Scotland, represents a range of metabolic disorders, presenting with heterogeneous aetiology, characterized by chronic hyperglycaemia and other metabolic abnormalities. According to Scottish diabetic framework over 160,000 people in Scotland have been diagnosed with diabetes ${ }^{3}$.However, these are clinically diagnosed cases but there could be many which are clinically unproven or borderline cases in the community. In Scotland diabetic patients aged 17 or more than 17 are $67 \%$ of total diabetic population in which $23 \%$ are hypertensive, $5.8 \%$ are with coronary heart diseases (CHD) and $3.8 \%$ are with

* Corresponding author:

dr.zeeshan_jmch@yahoo.com (Zeeshan Ahmed)

Published online at http://journal.sapub.org/phr

Copyright (C) 2012 Scientific \& Academic Publishing. All Rights Reserved
CHD and hypertension as well. ${ }^{4}$ Effective health education in diabetic population may produce changes in the knowledge and understanding about their illness and management; it may even effect changes in lifestyle that is very important for diabetes management. Despite it long clinical success this approach has only been applied in few centres and used by health care professionals. The role and impact of health education in diabetes is not having clarity, this could be probably because of not enough cost effective interventional studies with the use of health educators in diabetic care. The purpose of this paper to review the role of health education, self-management and multidisciplinary approach and how can improve to produce a framework for better practice.

\section{Practices about Self-Managing Diabetes}

Diabetes self-management education has been considered as an important part of the clinical management of individuals with diabetes since the $1930 \mathrm{~s}^{5}$. Approximately 40 years before Donnell Etzwiler first time established an outpatient education centre to provide basic diabetic information and self-management education to the diabetic patients. The team was comprised of three members, a dietician, nurse and physician ${ }^{6}$.The main focus of diabetes 
self-management education is to develop skill to improve glycaemic control, information and knowledge about life style changes such as diet and physical activity, and most important is to develop skill to prevent and identify late complication of diabetes such as diabetic foot and care ${ }^{7}$. The diabetic condition is such that majority are diagnosed either when they manifest with the clinical symptoms or accidently diagnosed when the patients arrive to hospital for other clinical conditions. Once they are diagnosed the treatment and management of diabetic care is usually expensive. Given the size of diabetic problem in the community, there are huge direct and indirect costs involved as the nature of diabetic condition is non-curable but only manageable condition. Chronic diabetic management is largely non clinical interventions such as dietary habits, physical exercise, stress relief and significant number of diabetic conditions could be managed by non-clinical supportive measures ${ }^{7}$.To strengthen the non-clinical intervention; health education plays a pivotal role. Self-management education is the process of teaching people to manage their diabetes and to optimize metabolic control and quality of life and to prevent acute and chronic complications, while keeping costs acceptable ${ }^{8}$. In short the diabetic condition needs cost effective community or individual educational intervention to attain effective care in diabetes.

\subsection{Current Practices about Diabetes Management}

The current hospital care of diabetes is more focussed on biomedical intervention. The specialists in the hospital are unable to give enough time and pay attention for non-clinical management of diabetes. Therefore, the focus has been given more for non-medical, cost effective, multidisciplinary team approach to manage the diabetes. Multidisciplinary approach to manage diabetic patients is essential at regular interval. Effective community based health education to care the diabetes themselves within multidisciplinary team with appropriate use of standard guidelines and research evidence for educational tools supported by regular monitored data on continuous basis would reduce the economic burden on patients as well as health care institutions. There is enough available evidence that the diabetes can be managed largely by proper diet, exercise and treatment monitoring empowering patients through education ${ }^{9}$.This can improve cost effective management in large scale diabetic care patients and supports to achieve the sustainability of the programme in the long run.

\subsection{Analytical Framework of Diabetes Self-Management}

The analytical framework for diabetes self-management education interventions have identified short term outcomes such as weight control, blood pressure control, number of visits and long term outcomes such as decrease morbidity, mortality and quality of life. Health educator plays an important role within multidisciplinary team of diabetic care such as consultant, researcher, clinician, nurse. Health educator would function as a change agent to manage the dia- betic self-care management. A meta-analytical study result on glycaeted hemoglobin in type II diabetes by concludes that self-education improves management of glycaeted hemoglobin levels after immediate follow up, and increases the effect with increased number of contacts ${ }^{10}$. This shows that diabetic health educator can play significant role in a multid isciplinary approach of diabetes self-care management as mentioned in the analytical framework for diabetes self-management education intervention. The experienced diabetic self-educator could occupy a significant connecting position by which diabetic health educator enable to perform patient education as well as bring changes in implementation of cost effective diabetic care through government supportive guidelines. National diabetic framework of Scotland has further supported by giving first priorities to the patient education, information and empowerment ${ }^{11}$. Diabetic education and self-management for old and newly diagnosed cases (DESMOND) is a collaborative team work to improve opportunities for learning to support for people with diabetes and the health care professionals. There are currently 430 diabetic health educators delivering education programme. Since for the past 12 month NHS has expanded beyond England and continues to grow throughout Scotland with over 40 health educators in West Lothian and Glasgow $^{12}$.

\subsection{Evidence from Literature}

A randomized cross sectional study conducted on 172 participants to compare the knowledge of diabetes in diabetic patients and healthy adults shown that diabetic patients were significantly much more familiar with the risk factors, signs, symptoms, co mplications and management of diabetes than healthy individuals because of health educa$\operatorname{tion}^{13}$. Therefore for the primary prevention of diabetes in community as well as proper management of diagnosed diabetes, there is a need to introduce health education and awareness programme by well-trained health educators. Diabetic health educator can act as a catalyst for prospective changes and also can effectively position themselves to work effectively with experts, hospital managers and patients. Nevertheless, diabetes health educators are in a unique position, they enable to support clinical work and innovative changes through cost-effective measures to the diabetic patients.

\subsection{Cost of Care on Diabetes Management}

Diabetes related cost on health care system is substantially increased due to long term diabetic complications management ${ }^{14}$. However, patient's education can reduce the health care cost by reducing the expenditure on diabetic complications management ${ }^{15}$. Diabetic health educator's role is preventive and cost effective self-care management based on diabetic educational training evidence to strengthen service delivery. Collective reflective practice will further enable the multidiscip linary team members to strike the balance as an active creator, finding solution to 
the existing barrier for effective practice, that constitute comprehensive economical diabetic care. The patients who are living too far away, have transport inconvenience or time management problem; they can get comprehensive education through telephone counseling as well. A randomized control study ${ }^{16}$ conducted to determine whether diabetes education can be provided as effectively through telemedicine technology as through in-person have shown that the both the telephonic and in person are equally effective. The study had total of 56 adults with diabetes, randomized to receive diabetes education in person (control group) or via telemedicine (telemedicine group) and were followed prospectively. The result of the study shows that diabetes education via telemedicine and in person was equally effective in improving glycaemic control, and both methods were well accepted by patients. Therefore, the NHS can effectively use modern crosscutting information technologies to provide diabetes education to patients.

In general, men and women needs similar diabetes education both in community or at health education centres while literature suggest that there is psychosocial, behavioural, and Clinical differences between men and women. This is further supported by a cross-sectional study ${ }^{17}$ that conducted to evaluate the gender difference in outcomes of diabetic education in type 2 diabetic patients. The result of study shows that women are more likely to have a family history of diabetes, previous diabetes education, and higher expectations of the benefits of self-management. Study provides evidence that diabetes prevention, care, and education need to be targeted to men and women differently. Primary care providers should encourage men to attend diabetes self-management education sessions and emphasize the benefits of self-care.

\section{Need of Practice Change}

Though there is enough evidence on health education for self-care management of diabetes but there is not much persuasion to implement in practice. Nearly all the barriers to effective self-diabetic management lie not in health system but in the individual's personal and social world. ${ }^{18}$ However, still there is much restriction to promote health education in diabetes self-care management.

Diabetes self-management education is a critical component of diabetes treatment ${ }^{19}$. Diabetes health educator having several challenges in front of national health service system such as influencing to define the role, policy, promotion to adopt health education and acceptance of patients. The development of counselling skills can compensate for the lack of traditional health education provided for diabetes patients and plays a significant part in the prevention of acute and chronic complications. Self-efficacy counselling strategies involve: asking questions; focusing on patient's agenda; planning personal treatment schedules; defining problems; setting goals (taking a step-by-step approach); regular follow-up and contact with patients; scaling ques- tions; brainstorming solutions; considering past efforts, successes and failures; reassessing confidence; and finally checking behaviour changes ${ }^{20}$.

\subsection{Way Forward from the Existing Scenario with the Help of Scientific Evidence}

The current hospital based diabetic care situation seems to continue without greater changes, therefore emphas is has to be made on essentials of diabetic health educators and need to reflect on the role with deeper analys is for future cost effective diabetic self-care management. So that there would be better understanding of their role to meet future challenges toward growing economic concerns of diabetic care effectively. Current educational research reflects the importance of emphasizing practical, problem solving skills, collaborative care, psychosocial issues, behavior change, and strategies to sustain self-management efforts ${ }^{21}$. Davies et al. conducted a multicentre cluster randomised control trial in to determine the impact of structured group education programme in newly diagnosed type 2 patients ${ }^{22}$. Total 824 patients participated in the study in which 55\% was men with mean aged 59.5 years. The result of the study concluded that structured group education in newly diagnosed patients is very effective, especially in weight loss and smoking cessation and positive improvements in beliefs about their illness.

Patients often complained that they need more information from health care providers or they do not receive adequate education regarding their particular needs ${ }^{23}$. Well trained, experienced diabetic care health educator will effectively draw right resources and appropriate knowledge for proper guide and action in diabetic care. Documentation of the organizational structure, mis sion statement, and goals can lead to efficient and effective provision of diabetes self-management education ${ }^{24}$.

\subsection{Mul ti-disciplin ary Approach}

Multidisciplinary supportive system such as Diabetes Specialist, Nutritionist, Nurses, Pharmac ist, Physiotherapist and Podiatrist would further enhance health educator's role. The management of diabetes mellitus not only requires the prescription of the appropriate nutritional and pharmacological regimen by the physician but also requires intensive education and counselling of the patient ${ }^{25}$. Inter professional approaches to patient care are believed to have the potential for improving professional relationships, increases efficiency and co-ordination, ultimately enhancing patient and health outcomes ${ }^{26}$. Nevertheless, health educator will effectively cope with the problem through multidisciplinary supportive system, can build appropriate relationship within the mu ltid isciplinary team me mbers to work collaboratively and consult with one another to achieve the shared objectives ${ }^{27}$. Hence proper reflective practice of health educator role is essential to create relationship with multidisciplinary team, so that diabetic self-care education and practice could meaningfully unfold. The team should have a collective 
combination of expertise in the clinical care of diabetes, medical nutrition therapy, educational methodologies, teaching strategies, and the psychosocial and behavioral aspects of diabetes self-management but diabetic educationist can be linkage to all the sub-disciplines of the teamwork. Diabetic educator can also play role in referral mechanism to ensure that the individual with diabetes receives education from those with appropriate training and credentials $^{28}$

Reflective practice will further set the tone for future practice by overcoming constraints which are encountered during practice. Diabetes self-management education is the ongoing process of to facilitate the knowledge, skill, and ability for diabetes self-care. The process of health education role in diabetes management need to incorporate the goals, and life experiences of the person with diabetes and be guided by evidence based standards ${ }^{28}$. The reflective practices will not only instil the faith and confidence in diabetic educators but also enables to practice appropriately.

\section{Future Challenges}

The health administration should take lead role: in balancing with appropriate skill mix to manage diabetes; clarity of role; responsibility; remuneration compensation and other administrative challenges to strengthen the role of health educator in diabetic self-care management in future. Scotland is one among few countries those providing free health services to their country people. Since concerns on cost of chronic disease such as diabetes is essential element for health system to manage effectively, the National health system needs to improve its services by enhancing effectiveness and efficiency to care the patients by strengthening supplementary services such as diabetic health education..$^{29}$

\subsection{Cost Effective Measures about Self-Management of Diabetes}

Current challenge for NHS is to provide cost effective service for the people suffering from chronic diseases such as diabetic care. Hence there has been continuous effort to improve the cost effective services by NHS. With the advent of modern information technology can further bridge the gap to overcome from communication/information barrier to implement cost effective services. A recent study found that a high proportion of patients are willing to use Internet resources in the management of their disease $\mathrm{e}^{30}$. Hence information technology can further strengthen the services to chronic diabetic patients by virtual continuous monitoring and health education supportive system. Internet-based diabetes management systems have the potential of reducing the burden of disease management cost, both to the patient and to the health care system. ${ }^{31}$ In short, the primary challenge is to mainstream the health education role in diabetic care to provide cost effective services.

\subsection{Role of Diabetic Health Educator}

Second challenge would be promotion of health educa- tion and enhancement of acceptance within health care professionals. The survey point out that diabetic patient in general had a better understanding of and appreciated the role of diabetic health educators. In contrast other health professionals such as physicians, health authorities and others are still unclear about the role of diabetes educators ${ }^{32}$. There is a need to bring clarity on health educator role, title of structure and position within NHS. This will play a significant role to motivate health educator work force in long term strategy.

\subsection{Acceptance of the Role of Diabetic Health Educator by Patients}

Third challenge is to make understand the role of health educator by patients. In seeking to enhance patient safety, health educators face a number of challenges. To successfully manage those, health educators must expand their knowledge, broaden connections, and engage patients and families in meaningful ways ${ }^{33}$. The delivery of health care is undergoing constant change and patient expectation, professional accountability, and interdisciplinary teamwork are now the paramount drivers. Diabetes education delivered by well-trained healthcare professionals becomes integrated with clinical care, forming the key to successful self-management on the part of the person with diabetes. ${ }^{33}$

\subsection{Promotion of Health Education in the Community}

Nevertheless, the promotion of health education towards diabetic care should be promoted in the community to raise the awareness. Health educators possess a skill set and an ethical framework that effectively equip them to advance patient and family-centred care and contribute in other significant ways to a safer health care system ${ }^{33}$. This community education will lay foundation stone for sustainability of the programme.

Considerable number of people in Scotland belongs to minority group (Non English speaking community) about 2\% of the total population of Scotland ${ }^{34}$. Poor blood glucose control and suboptimal self-management have been observed more frequently in racial and ethnic minorities and are associated with a lower frequency of self-monitoring of blood glucose in adults with diabetes ${ }^{35}$. Therefore customization of guidelines and education material should be context and cultural specific in their native languages are an essential element to be considered.

\section{Conclusions}

The study has gone some way towards enhancing our understanding of the importance of self-management, multidisciplinary approach and health education. Diabetic health educator can effectively collaborate and build linkage with patients, consultants, general practitioners, researcher and other nursing care professionals for cost effective diabetic patient care. Furthermore, the role of educator is vital, they can play as a catalyst, changing agent to strengthen the patient care. It is essential that national health 
system and health institutions have to create appropriate diabetic educator to meet growing diabetic care issue to provide cost effective services.

The study provides greater insight about the importance of patient education from health professionals. In fact, multimedia cannot replace the human power such as physicians, nurses, dieticians and other healthcare professionals in delivery of health education but internet or computer based education will play a significant role in cost-effective diabetes health care programme ${ }^{36}$. After various studies it has been established that patient education and self-care management is vital for better management of diabetes but what is the most effective way of health education is still unclear.

There is a need for well-designed intervention studies on the effect of different aspects of education on adherence to treatment recommendations. Appropriate reflective changes are essentials for positive step to understand and initiate health educator role in diabetic care. In order to achieve better outcomes and effective health care services, collaboration of different health care professional working in different setup is required.

\section{Key Points}

- Patients as partners

- Health and Learning: Develop expert patients

- Self-care management and patient empowerment: Planning personal treatment schedules

- Multidiscip linary approach

- Balanced diet

- Culture change: Life style modification

\section{REFERENCES}

[1] Bethesda. National Institute of Diabetes and Digestive and Kidney Diseases: National diabetes statistics fact sheet: general information and national estimates on diabetes in the United States, U.S. Department of Health and Human Services, National Institutes of Health [Online]2003. Available from: http://diabetes.niddk.nih.gov/dm/pubs/statistics/index. htm\#17 [Accessed June 05 2009]

[2] WHO. Diabetes the problem [Online] 2006. Available from:http://www.who.int/nmh/publications/facts_sheet_diab etes_en_pdf [Accessed June 22 2009]

[3] SDF. Diabetes in Scotland: Current challenges and future opportunities. Reviewing the Scottish Diabetes Framework [online] 2004. Available from:http://www.scotland.gov.uk/P ublications/2004/11/20236/46458[Accessed April 1 2009]

[4] PTI and QOF. Information and statistic: General Practice Practice Team Information (PTI) [online] 2008. Available from: $\quad<$ http://www.isdscotland.org/isd/3747.html $\quad$ [Accessed May 4 2009]

[5] Bartlett E. Historical glimpses of patient education in the United States. Patient Educ Counsel 1986, 8:135-149

[6] Powers MA, Carstensen K, Colon K, Rickheim P, Bergens- tal RM. Diabetes BASICS: Education, Innovation, and Revolution. Diabetes Spectrum 2006, 19(2):90-98

[7] Norris SL, Engelgau MM, Naray an KM. Effectiveness of Self-Management Training in Type 2 Diabetes. Diabetes Care2001,24 (3):561-587

[8] Norris SL, Nichols PJ, Caspersen CJ, Glasgow RE, Engelgau MM, Jack L, Snyder SR, Carande-Kulis VG, Isham G, Garfield S, Briss P, McCulloch D.. Increasing Diabetes Self-Management Education in Community Settings. Am J Prev Med2002, 22 (4):39-66

[9] Loveman E, Cave C, Green C, Royle P, Dunn N, Waugh N.. The clinical and cost-effectiveness of patient education models for diabetes: a systematic review and economic evaluation. Health Technology Assessment2003. 7 (22):1-190.

[10] Norris SL, Lau JL, Smith SJ, Schmid CH, Engelgau MM. Self-Management Education for Adults With Type 2 Diabetes, Diabetes Care 2002,25:1159-1171

[11] SDF. Working together with healthy, caring Scotland [online] 2006. Available from:http://www.scotland.gov.uk/Resource/ Doc/46905/0033884.pdf[Accessed April 04 2009]

[12] DESMOND. Developing quality structured education in diabetes. Providing award winning training [online] 2008. Available from:http://www.desmond-project.org.uk/index.ht ml[Accessed April 09 2009]

[13] Yun LS, Hassan Y,Abd Aziz N, Awaisu A, Ghazali R.A comparison of knowledge of diabetes mellitus between patients with diabetes and healthy adults: A survey from north Malaysia. Patient Education and counselling2007, 69:47-54

[14] Clarke P, Gray A, Legood R, Briggs A, Holman R.. The impact of diabetes-related complications on healthcare costs: results from the United Kingdom Prospective Diabetes Study (UKPDS Study No. 65). Diabetic Medicine2003, 20:442-450.

[15] Herman WH, Eastman RC. The effects of treatment on the direct costs of diabetes. Diabetes Care1998, 21:19-24

[16] Izquierdo RE, Knudson PE, Meyer S, Kearns J, Ploutz-Snyder R, Weinstock RS. A Comparison of Diabetes Education Administered Through Telemedicine Versus in Person. Diabetes Care 2003,26 (4):1002-1007

[17] Gucciardi E, Wang WC, DeMelo M, Amaral L, Stewart DE. Characteristics of men and women with diabetes: Observations during patients' initial visit to a diabetes education center. Can Fam Physician 2008, 54:219-27

[18] Cradock S. Helping patients to improve self-management of diabetes. Heart 2004, 90:36-38

[19] Jack L. Diabetes Self-Management Education Research: An international review of intervention methods, theories, community partners and outcomes. Disease Management and Health Outcomes 2003, 11:415-428

[20] Wang SF, Li YC, Chang JR, Courtney M, Chang YL. The application of self-efficacy counseling skills to health education in patients with diabetes. The Journal of Nursing 2007, 54:70-77

[21] Siminerio L, Piatt G, Emerson S, Ruppert K, Saul M, Solano F, Stewart A, Zgibor J. Deploying the chronic care model to 
implement and sustain diabetes self-management training programs. Diabetes Educ2006, 32:1- 8

[22] Davies MJ, Heller S, Skinner TC, Campbell MJ, Carey ME, Cradock S, Dallosso HM, Daly H, Doherty Y, Eaton S, Fox C, Oliver L, Rantell K. Effectiveness of the diabetes education and self-management for ongoing and newly diagnosed (DESMOND) programme for people with newly diagnosed type 2 diabetes: cluster randomised controlled trial. BMJ2008, 336:491-495

[23] Boberg EW, Gustafson DH, Hawkins RP, Offord KP, Koch C, Wen KY. Assessing the unmet information, support and care delivery needs of men with prostate cancer. Patient Education and Counselin2003, 49(3):233-242

[24] Renders CM, Valk GD, Griffin SJ, Wagner EH, Eijk van JT, Assendelft WJJ. Interventions to improve the management of diabetes in primary care, outpatient, and community settings: a systematic review. Diabetes Care2001, 24:1821-1833

[25] Nuttal FQ. Carbohydrate and Dietary Management of Individuals with Insulin Requiring Diabetes. Diabetes Care1993, 16:1039-1042

[26] Curran VR, Sharpe D, Forristall J. Attitudes of health sciences faculty members towards interprofessional teamwork and education. Medical Education2007, 41:892

[27] Skovlund SE, Peyrot M. care. Diabetes Spectrum 2005, 18(3):136-142

[28] Funnell MM, Brown TL, Childs BP. et al. National Standards for Diabetes Self-Management Education. Diabetes Care2008, 31 (1):97-104
[29] NHS. Quality improvement Scotland: Action needed to improve diabetic care [online] 2004. Available from: http://www.nhshealthquality.org/nhsqis/1286.html[Accessed April 01 2009]

[30] Feil EG, Glas gow RE, Boles S, Mckay HG. Who participates in Internet-based self-management programs? A study among novice computer users in a primary care setting. $D i$ abetes Educ2000, 26(5):806-811

[31] Mazzi CP. A Framework for the Evaluation of Internet-based Diabetes Management. J Med Internet Res2002, 4(1):123- 130

[32] IDF. Diabetes atlas: diabetes education, educational practices, survey results [online] 2006. Available from: http://www.eatlas.idf.org/Diabetes_education/Educational_p ractices/Survey_results/ [Accessed Sep 05 2009]

[33] Mercurio A. The Evolving Role of Health Educators in Advancing Patient Safety: Health PromotPract.2007, 8: 119-127

[34] McGill M. Educating the Educators: An International Curriculum for Health Professionals in Diabetes. Diabetes Voice2002, 47(4):33-34

[35] NHS. Diabetes in minority ethnic group in Scotland: Summary Report [online] 2004. Available from: http://www.nrcemh.nhsscotland.com/pdfs/Summary\%20Dia betes\%20Report.pdf [Accessed April 06 2009]

[36] Anderson RM. Into the heart of darkness: reflections on racism and diabetes care. Diabetes Educ1998, 24:689-692

[37] Richards B, Colman AW, Hollingsworth RA. The current and future role of the internet in patient education. International Journal of Medical Informatics 1998, 50:279-285 